\title{
European League Against Rheumatism recommendations for the management of psoriatic arthritis with pharmacological therapies
}

\author{
L Gossec, ${ }^{1,2}$ J S Smolen, ${ }^{3,4}$ C Gaujoux-Viala, 5,6 Z Ash, 7,8 H Marzo-Ortega, 7,8 \\ $\mathrm{D}$ van der Heijde, ${ }^{9} \mathrm{O}$ FitzGerald, ${ }^{10} \mathrm{D}$ Aletaha, ${ }^{3} \mathrm{P}$ Balint, ${ }^{11} \mathrm{D}$ Boumpas, ${ }^{12} \mathrm{~J} \mathrm{Braun}^{13}$ \\ F C Breedveld ${ }^{9}{ }^{G}$ Burmester, ${ }^{14}$ J D Cañete, ${ }^{15} \mathrm{M}$ de Wit, ${ }^{16}$ H Dagfinrud, ${ }^{17,18}$ \\ $\mathrm{K}$ de Vlam, ${ }^{19} \mathrm{M}$ Dougados, ${ }^{1,2} \mathrm{P}$ Helliwell, ${ }^{7} \mathrm{~A}$ Kavanaugh, ${ }^{20} \mathrm{~T} \mathrm{~K}$ Kvien, ${ }^{17,18} \mathrm{R}$ Landewé, $^{21}$ \\ T Luger, ${ }^{22}$ M Maccarone, ${ }^{23}$ D McGonagle, ${ }^{7,8}$ N McHugh, ${ }^{24}$ I B McInnes, ${ }^{25}$ C Ritchlin, ${ }^{26}$ \\ J Sieper, ${ }^{27}$ P P Tak, ${ }^{28} \mathrm{G}$ Valesini, ${ }^{29} \mathrm{~J}$ Vencovsky, ${ }^{30} \mathrm{~K} \mathrm{~L} \mathrm{Winthrop,}{ }^{31}$ A Zink, ${ }^{32,33}$ \\ P Emery, 7,8
}

\begin{abstract}
- Additional supplementary data are published online only. To view these files please visit the journal online (http://ard. bmj.com/content/71/1.toc).

For numbered affi liations see
\end{abstract} end of article

\section{Correspondence to}

Dr Laure Gossec, Service de Rhumatologie B, Hôpital Cochin, 27, rue du Faubourg SaintJacques, 75014 Paris, France; laure.gossec@cch.aphp.fr

LG and JSS contributed equally to the study (joint first authors)

Accepted 4 August 2011 Published Online First 27 September 2011

\section{UNLOCKID}

This paper is freely available online under the BMJ Journals unlocked scheme, see http:// ard.bmj.com/info/unlocked.dtl

\begin{abstract}
Background Psoriatic arthritis $(\mathrm{PSA})$ is a clinically heterogeneous disease. Clear consensual treatment guidance focused on the musculoskeletal manifestations of PsA would be advantageous. The authors present European League Against Rheumatism (EULAR) recommendations for the treatment of PsA with systemic or local (non-topical) symptomatic and disease-modifying antirheumatic drugs (DMARD).
\end{abstract}

Methods The recommendations are based on evidence from systematic literature reviews performed for non-steroidal anti-inflammatory drugs (NSAID), glucocorticoids, synthetic DMARD and biological DMARD. This evidence was discussed, summarised and recommendations were formulated by a task force comprising 35 representatives, and providing levels of evidence, strength of recommendations and levels of agreement.

Results Ten recommendations were developed for treatment from NSAID through synthetic DMARD to biological agents, accounting for articular and extraarticular manifestations of PSA. Five overarching principles and a research agenda were defined.

Conclusion These recommendations are intended to provide rheumatologists, patients and other stakeholders with a consensus on the pharmacological treatment of PsA and strategies to reach optimal outcomes, based on combining evidence and expert opinion. The research agenda informs directions within EULAR and other communities interested in PsA.

The treatment of psoriatic arthritis (PsA) has changed dramatically over recent years, despite the lack of sufficient knowledge on aetiology and detailed pathogenesis. Observations that pro-inflammatory cytokines may play important pathogenetic roles have led to the evaluation of novel therapies; indeed, new synthetic and biological disease-modifying antirheumatic drugs (DMARD) are widely used,,$^{1-5}$ with further treatment options anticipated in the near future. ${ }^{6} 7$ While psoriatic skin and joint disease have many facets in common, the pathways leading to their expression may differ, exemplified in the frequent distinct efficacy of various therapies on skin and joint disease (eg, phototherapy, fumaric acid or alefacept). ${ }^{8-12}$ PsA in itself is heterogeneous by virtue of its broad phenotypes of joint involvement (peripheral and spinal), ${ }^{13}$ but also its spectrum of extra-articular manifestations, which — aside from skin and nailscomprise dactylitis and enthesopathy.14 15

The complexity of PsA and the relative paucity of randomised controlled clinical studies, let alone strategic trials, contrasts with the situation in rheumatoid arthritis (RA), another chronic and destructive inflammatory joint disease. There are data on the usefulness of synthetic DMARD as well as the efficacy of biological DMARD, particularly tumour necrosis factor (TNF) inhibitors ${ }^{1-5}{ }^{16-18}$ in PsA, and there exist general recommendations for the use of biological agents. ${ }^{19}$ Recently, recommendations for PsA treatment were presented by the Group for Research and Assessment of Psoriasis and Psoriatic Arthritis (GRAPPA). ${ }^{20} 21$ These recommendations are comprehensive, with a special focus on skin disease, providing an initial treatment guidance set. However, clinicians can benefit from concise, easy to follow guidance on the optimal use of available therapies and clear treatment strategies for PsA.

Among other aspects, the efficacy of synthetic DMARD and the role of glucocorticoids remain under debate, and combination therapy of synthetic DMARD or synthetic DMARD with biological agents is relatively underresearched. ${ }^{17} 22$ Moreover, even disease activity assessment of PsA is under scrutiny, given that the measures used in clinical trials are mostly 'borrowed' from $\mathrm{RA}^{23}$ with further methods under evaluation. Furthermore, therapeutic targets require definition. ${ }^{24} 25$

All of these reasons, as well as more recent insights, provided a rationale for the development of European League Against Rheumatism (EULAR) recommendations for the management of PsA. Rheumatologists require evidence-based guidance for the treatment of PsA with regard to synthetic and biological therapies, including the definition of treatment targets and assessment tools.

To address the set task, EULAR convened a group of experts to produce evidence-based recommendations for the management of PsA with non-topical pharmacological therapies on the basis 
of the EULAR standard operating procedures, ${ }^{26}$ and to develop a research agenda for future activities.

\section{METHODS}

The task force aimed at aggregating available information on disease management in PsA into practical recommendations. The basis of its activities were the respective EULAR standardised procedures, ${ }^{26}$ which suggest the institution of an expert committee in charge of consensus finding, on the basis of evidence provided by a systematic literature review and expert opinion. The taskforce thus followed a similar path as other management recommendations, such as for RA, ankylosing spondylitis and osteoarthritis. ${ }^{27-30}$ One of the aims of EULAR recommendations is to provide clear guidance that is easy to follow in clinical practice.

The expert committee consisted of 28 rheumatologists, two patients, one infectious disease specialist, one dermatologist, one physiotherapist and two rheumatology fellows. The members of this task force came from 14 European countries and from the USA. This inclusive approach aimed at obtaining broad consensus and applicability of the recommendations. The process was both evidenced based and consensus based, as explained in supplementary text 1 (available online only), and included, between January 2010 and December 2010, two expert meetings, systematic literature reviews and extensive discussions. The literature search is published separately. ${ }^{31}$

A vote was obtained from the experts on the level of agreement with the final recommendations. Votes for agreement or disagreement were performed anonymously, by giving a score from 0 (total disagreement) to 10 (total agreement) for each recommendation; the means and SD of scores from the whole group were calculated.

\section{RESULTS \\ Overarching principles}

Before addressing the actual treatment recommendations, the task force established principles deemed sufficiently important to be conveyed to those affected by PsA or involved with the management of PsA. These principles regarding the care of patients with PsA are of such s generic nature that they were felt to be 'overarching'. The complete wording and level of agreement are shown in table 1 , and the explanatory text is in supplementary text 2 (available online only). The task force voted unanimously on these five principles.

\section{Recommendations}

The process led to 10 recommendations on drug management and treatment strategies, presented in table 1 with levels of evidence and strengths of recommendations. The 10 recommendations are ordered by means of logical sequence or procedural and chronological hierarchy rather than by any major weight of importance. They also serve as the basis for the algorithm provided in figure 1.

\section{NSAID for relief of signs and symptoms}

The task force was unanimous in its view that in the vast majority of PsA patients, NSAID should be used as first-line treatment, although the data regarding the usefulness of NSAID in PsA are limited. ${ }^{31-33}$ NSAID have been shown to be efficacious on joint symptoms, although there is no demonstrated efficacy on skin lesions. ${ }^{31}$ Of course, cardiovascular and gastrointestinal risk ${ }^{34-36}$ should be taken into account when prescribing NSAID, which explains the use of the word 'may' in the wording of the recommendation. Furthermore, not everyone with signs and symptoms requires NSAID treatment, as some patients may respond well to analgesics or may not feel in need of symptomatic therapy. We encourage the lowest dose and the shortest treatment duration possible with NSAID, in view of their potential toxicity. Data suggest that cyclooxygenase 2 inhibitors are as effective as nonselective NSAID in PsA. ${ }^{32}$ No data were found regarding the possible worsening of skin lesions following NSAID use.

\section{Treatment with synthetic DMARD}

To date, there are few data on which to rest for the decision to start a synthetic DMARD. Who should be treated with DMARD? When to treat with DMARD? This should be addressed by future research. Based on the prognostic factors shown in the literature, the group considered that patients with active disease and potential poor prognosis should be started on DMARD. Active disease was defined globally as one or more tender and inflamed joint and/or tender enthesis point and/or dactylitic digit and/or inflammatory back pain; however, for the introduction of synthetic DMARD only joint involvement is taken into account. Poor prognosis refers here to the number of actively inflamed joints (defined here as five or more), elevated acute phase reactants, radiographic damage that is progressing, previous use of glucocorticoids, loss of function and diminished quality of life. ${ }^{31} 37$

Delay in the start of DMARD therapy may lead to worse outcomes, similar to RA, ${ }^{38}$ although data are scarce in this respect in PsA. ${ }^{20} 39$ Obviously, patients who have active disease despite previous NSAID therapy should receive a synthetic DMARD (this is stated as 'at an early stage' in the recommendation; although the term 'early' was not precisely defined, it is common to regard 'early' as a few weeks to a maximum of 1 year). Regarding the choice of a DMARD, here again there are few data and almost no head-to-head comparisons. Based on the available literature, the experts recommended methotrexate as the first-choice DMARD. This group decision was based in particular on broad therapeutic dose ranges, different application forms (by mouth, subcutaneous) and available data in PsA and in other inflammatory diseases. ${ }^{39-42}$ It is worth noting here that synthetic DMARD do not appear to be efficacious for treating enthesitis and axial disease (more details under recommendations 6 and 7 , see table 1).

When treating with methotrexate, careful consideration must be given to the prescription of an efficacious dose. While the most efficacious dose has not been determined for PsA and low doses may not be effective, it is evident in RA that doses in the order of $25 \mathrm{mg}$ per week are more appropriate than lower doses. ${ }^{43}$ Other drugs to be considered include sulfasalazine, leflunomide and ciclosporin A (although the use of this latter drug is limited by long-term toxicity issues). ${ }^{4} 22 \quad 3144-46$ The order presented here is not a ranking order. Clinical efficacy on joint involvement has also been published for gold salts and azathioprine, although for these drugs the level of evidence was low. ${ }^{31}$ None of the synthetic DMARD have been tested for (eg, ciclosporin, leflunomide) and/or have demonstrated (eg, methotrexate, sulfasalazine, gold salts, azathioprin) structural efficacy in PsA. ${ }^{31}$ Although there is a lack of evidence on the efficacy of synthetic DMARD combinations, these may be considered. ${ }^{47} 48$

As a result of the potential for increased hepatic toxicity of methotrexate in PsA compared with other rheumatic conditions, ${ }^{49} 50$ transaminase enzymes should be carefully monitored in patients with PsA who receive treatment with methotrexate or leflunomide, especially in cases of alcohol consumption, obesity, type II diabetes and non-alcoholic steatohepatitis or concurrent therapy with other potentially hepatotoxic drugs (eg, statins). In some patients, a liver biopsy has been recommended. ${ }^{51}$ 
Table 1 EULAR recommendations for the management of PsA, with levels of evidence, grade of recommendations and level of agreement

\begin{tabular}{|c|c|c|c|c|}
\hline & Overarching principles & & & $\begin{array}{l}\text { Level of } \\
\text { agreement } \\
\text { (mean } \pm \text { SD) }\end{array}$ \\
\hline A. & $\begin{array}{l}\text { Psoriatic arthritis is a heterogeneous and potentially severe disease, which may } \\
\text { require multidisciplinary treatment. }\end{array}$ & & & $9.8 \pm 0.5$ \\
\hline B. & $\begin{array}{l}\text { Treatment of psoriatic arthritis patients should aim at the best care and must be } \\
\text { based on a shared decision between the patient and the rheumatologist. }\end{array}$ & & & $9.8 \pm 0.8$ \\
\hline C. & $\begin{array}{l}\text { Rheumatologists are the specialists who should primarily care for the } \\
\text { musculoskeletal manifestations of patients with psoriatic arthritis; in the presence of } \\
\text { clinically significant skin involvement a rheumatologist and a dermatologist should } \\
\text { collaborate in diagnosis and management. }\end{array}$ & & & $9.6 \pm 0.8$ \\
\hline D. & $\begin{array}{l}\text { The primary goal of treating patients with psoriatic arthritis is to maximise long- } \\
\text { term health-related quality of life, through control of symptoms, prevention of } \\
\text { structural damage, normalisation of function and social participation; abrogation of } \\
\text { inflammation, targeted at remission, is an important component to achieve these } \\
\text { goals. }\end{array}$ & & & $9.7 \pm 0.6$ \\
\hline \multirow[t]{2}{*}{ E. } & Patients should be regularly monitored and treatment should be adjusted appropriately. & & & $9.7 \pm 0.7$ \\
\hline & Recommendations & Level of evidence & $\begin{array}{l}\text { Grade of } \\
\text { recommendation }\end{array}$ & $\begin{array}{l}\text { Level of } \\
\text { agreement } \\
\text { (mean } \pm \text { SD) }\end{array}$ \\
\hline 2. & $\begin{array}{l}\text { In patients with active disease (particularly those with many swollen joints, } \\
\text { structural damage in the presence of inflammation, high ESR/CRP and/or clinically } \\
\text { relevant extraarticular manifestations), treatment with disease-modifying drugs, } \\
\text { such as methotrexate, sulfasalazine, leflunomide, should be considered at an early } \\
\text { stage. }\end{array}$ & ${ }^{*} 1 \mathrm{~b}, \dagger 4$ & B & $9.4 \pm 0.7$ \\
\hline 3. & $\begin{array}{l}\text { In patients with active psoriatic arthritis and clinically relevant psoriasis, a disease- } \\
\text { modifying drug that also improves psoriasis, such as methotrexate, should be } \\
\text { preferred. }\end{array}$ & $1 \mathrm{~b}$ & A & $9.1 \pm 1.0$ \\
\hline 4. & $\begin{array}{l}\text { Local injections of corticosteroids should be considered as adjunctive therapy in } \\
\text { psoriatic arthritis; systemic steroids at the lowest effective dose may be used with } \\
\text { caution. }\end{array}$ & $\ddagger 3 \mathrm{~b}, \S 4$ & C & $8.9 \pm 1.2$ \\
\hline 5. & $\begin{array}{l}\text { In patients with active arthritis and an inadequate response to at least one synthetic } \\
\text { disease-modifying antirheumatic drug, such as methotrexate, therapy with a tumour } \\
\text { necrosis factor inhibitor should be commenced. }\end{array}$ & $1 \mathrm{~b}$ & B & $8.9 \pm 1.5$ \\
\hline 9. & $\begin{array}{l}\text { In patients who fail to respond adequately to one tumour necrosis factor inhibitor, } \\
\text { switching to another tumour necrosis factor inhibitor agent should be considered. }\end{array}$ & $2 b$ & B & $8.9 \pm 1.8$ \\
\hline 10. & $\begin{array}{l}\text { When adjusting therapy, factors apart from disease activity, such as comorbidities and safety } \\
\text { issues, should be taken into account. }\end{array}$ & 4 & D & $9.5 \pm 1.0$ \\
\hline
\end{tabular}

Recommendations with different levels of evidence within the recommendation are listed below.

The level of agreement was computed as a 0 to 10 scale, based on 28 voters within the group.

*In patients with active disease (particularly those with many swollen joints-usually $\geq 5$, structural damage in the presence of inflammation, high ESR/CRP and/or clinically relevant extra-articular manifestations), treatment with disease-modifying drugs, such as methotrexate, sulfasalazine, leflunomide, should be considered; tat an early stage.

¥ Local injections of corticosteroids should be considered as adjunctive therapy in psoriatic arthritis; §systemic steroids at the lowest effective dose may be used with caution.

CRP, C-reactive protein; ESR, erythrocyte sedimentation rate; EULAR, European League Against Rheumatism; PsA, psoriatic arthritis.

\section{Choice of synthetic DMARD in the presence of clinically relevant psoriasis}

Some DMARD have shown efficacy in psoriasis. This is especially the case with methotrexate, but also ciclosporin A, leflunomide and sulfasalazine. ${ }^{31} 52$ In patients with 'clinically relevant' psoriasis, defined as psoriasis with impact on quality of life, these data should be taken into account for the choice of DMARD. In trials, the extent of psoriasis is measured through composite indices such as the PASI (Psoriasis Area and Severity Index). However, these recommendations are mainly aimed at rheumatologists, who usually do not measure psoriasis by PASI. The extent of psoriasis (percentage of skin body surface) is an indicator of psoriasis severity; however, there are cases when the extent may not be important, but the consequences on quality of life are important (eg, face/hand/genital involvement). Therefore, we suggest considering the choice of DMARD in the light of patient-perceived severity of psoriasis (through its impact on quality of life). This would correspond in dermatological terms to moderate to severe psoriasis. Better understanding the patients' perspective in PsA was set on the research agenda.

\section{Local and systemic glucocorticoids}

Glucocorticoid injections may be a useful adjunctive therapy in localised disease (oligoarticular forms, enthesitis or dactylitis). ${ }^{53}$ Intra-articular steroids are efficacious for mono/oligoarthritis or single joint flares, in otherwise well-controlled polyarthritis. Glucocorticoid injections may also be performed in dactylitis (tendon sheath/peritendinous injections) and in entheseal 


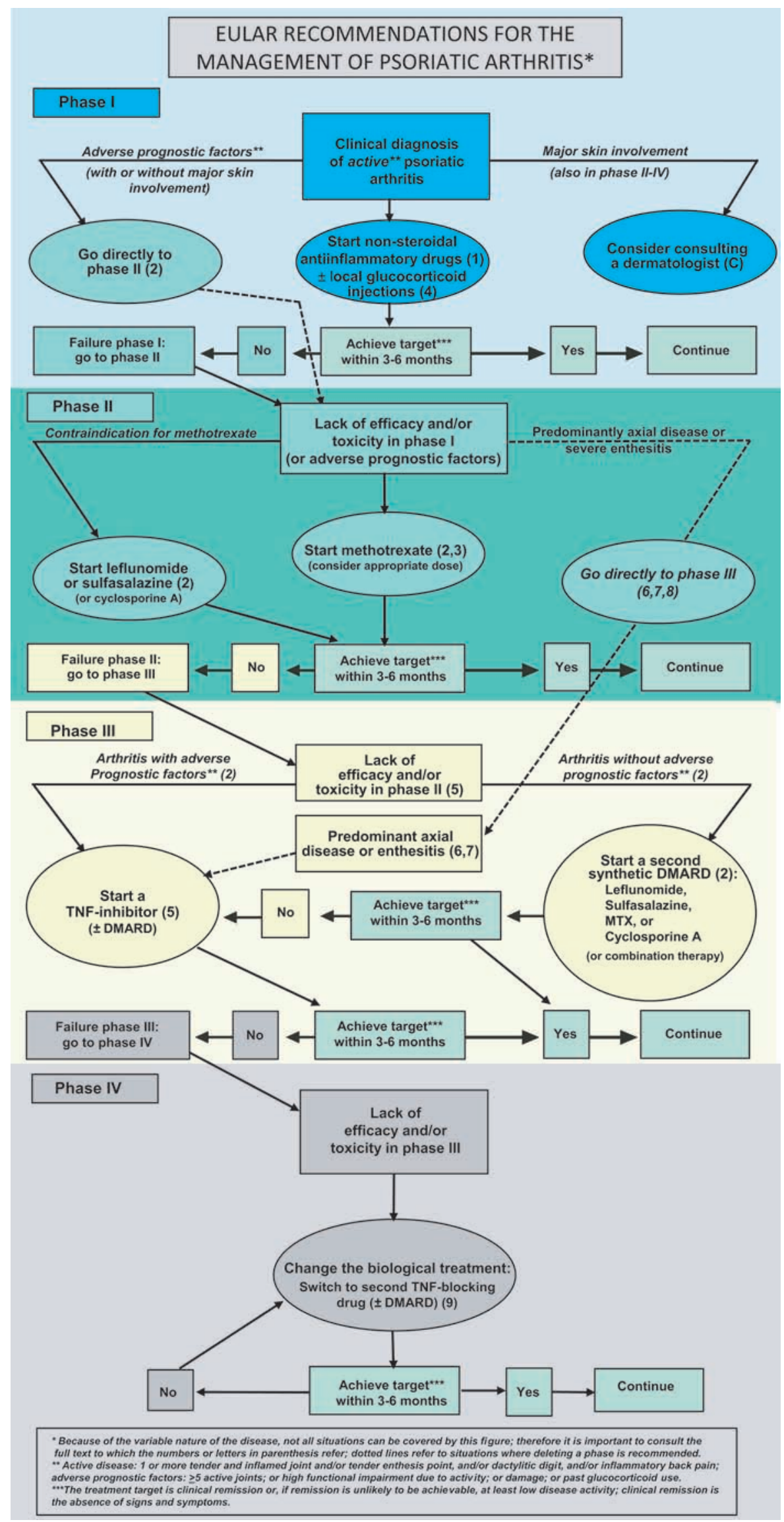

Figure 1 Management of psoriatic arthritis according to the European League Against Rheumatism recommendations. Recommendations have been divided into four phases. Numbers in parentheses indicate the respective items of the recommendation as shown in table 1. Small fonts within the ellipses in phases II and III refer to dose modifications or an alternative therapy, as detailed within the body of the recommendations. 
areas, for example, elbow, or retrocalcaneal bursa in Achilles enthesitis. $^{20}$

Systemic steroids in psoriasis are feared, as it has been reported that skin flares may occur. ${ }^{54}$ However, the literature search performed to inform the present recommendations found few data (other than case reports) supporting the assertion that skin psoriasis may flare in glucocorticoid-treated PsA patients. ${ }^{31}$ Furthermore, registry data reveal that systemic steroids are, in fact, widely used in PsA (up to $30 \%$ of patients in the German national database), usually at low doses ( $\leq 7.5 \mathrm{mg} /$ day), ${ }^{55}$ although there is no evidence from clinical trials on the efficacy of systemic glucocorticoids in PsA (level of evidence 4; table 1). Nevertheless, the task force considered that systemic glucocoritcoids are a therapeutic option, although they should be used with caution, keeping in mind the possibility of a skin flare. Greater caution should perhaps be used in patients with severe/ extensive skin involvement, and/or not taking concomitant DMARD (expert opinion). This stems partly from the observation that PASI scores in PsA trials are generally much lower than in clinical trials of psoriasis.

In PsA as in other chronic diseases, the long-term use of glucocorticoids can lead to major adverse events; ${ }^{56}$ therefore, thought should be given to tapering glucocorticoids when feasible. When tapering, attention should be paid to the potential worsening of skin disease (rebound). The safety of glucocorticoids is also an important aspect of the EULAR recommendations on the management of glucocorticoid therapy. ${ }^{57}$

\section{TNF inhibitors}

This recommendation deals with patients for whom a synthetic DMARD (usually methotrexate because of its effects on joints and skin, but also leflunomide, sulfasalazine or others, see above) is not efficacious or not well tolerated. A patient should be considered a treatment failure when in spite of therapy for a length of time appropriate to the drug profile (usually $3-6$ months), the patient fails to demonstrate achievement of the treatment target low disease activity. Treatment failure could not be defined more precisely given the lack of appropriate trials. In these patients TNF inhibitor treatment (with or without continuation of previous synthetic DMARD therapy) can be considered if the disease is active, ie, if there is evidence of active arthritis in terms of swollen joints and/or at least moderate disease activity by a composite disease activity measure and/or active disease with impaired function or quality of life. However, the definition of (residual) active disease is still pending in PsA, and is part of the research agenda.

This item refers to the use of biological agents. TNF inhibitors (adalimumab, etanercept, golimumab and infliximab) have demonstrated efficacy in PsA, both for skin and joint involvement, as well as in preventing radiographic damage. 561631 There were no evident differences regarding the efficacy of the different TNF inhibitors on the joints, although no head-to-head comparisons exist. ${ }^{58}$ However, for skin involvement, it seems that the efficacy of the TNF receptor construct etanercept on psoriasis may be lower, or at least be of slower onset, than for the antibodies targeting TNF (although there are, again, no headto-head comparisons available). ${ }^{2}$ Also, ustekinumab was tested against etanercept in patients with psoriasis and demonstrated superior skin outcomes after 12 weeks. ${ }^{59}$ This information may be taken into consideration for the choice of TNF inhibitors in patients with clinically significant skin involvement.

Other biological agents have been assessed in PsA but there were too few data (ustekinumab, rituximab, abatacept, tocilizumab) and/or too low response rates (alefacept) to consider these drugs in this recommendation. ${ }^{31}$ The list of biological agents must of course be updated regularly, as new data are published.

To date, there are no data showing the superiority of TNF inhibitors in combination with synthetic DMARD versus TNF inhibitor monotherapy. ${ }^{3} 51$ Of note, in all trials of TNF inhibitors in PsA, methotrexate was allowed but not required, and approximately half the patients in these studies took TNF inhibitor monotherapy without concomitant methotrexate. The data for patients receiving and not receiving methotrexate were comparable. ${ }^{60}$ This was added to the research agenda. TNF inhibitors also improve enthesitis and axial disease (see also recommendations 6 and 7).

Regarding the safety of biological agents in PsA, there are significantly fewer data available than in RA. ${ }^{31}{ }^{61-63}$ Indeed, there are few data available regarding even the background risk of infectious disease morbidity in PsA/psoriasis. Given the paucity of safety data on biological agents in PsA, one option is to extrapolate from either the RA or psoriasis experience with these therapies. In RA, there is now a wealth of safety data from randomised controlled trials and, most importantly, from large observational studies (registry data). In comparison, however, there is a lack of long-term safety data on TNF inhibitors in the psoriasis setting. Data to date suggest that the biological agents are likely to have a similar risk profile in PsA and psoriasis with regard to serious adverse events (eg, elevated infectious risk), but that the absolute risks of infection and malignancy (and perhaps other serious adverse events) are probably lower than in RA, due to underlying pathophysiological differences between RA and psoriasis. Long-term registry or other observational data will be important to establish the safety profile of these drugs in PsA or psoriasis. However, to date, the literature review did not find any apparent specific safety signals of concern in PsA, compared with RA. As stated in this recommendation, in patients with active arthritis, TNF inhibitors should be 'considered'; of course, we recommend careful assessment of potential contraindications to TNF inhibitors and careful weighing of the benefit/risk/cost ratio before any treatment decision is made (please see also recommendation 10, see table 1).

\section{Enthesitis and/or dactylitis and TNF inhibitors}

This recommendation deals with the subgroup of patients with predominant enthesitis/dactylitis. In these patients, TNF inhibitors might be considered even if no synthetic DMARD have been tried, after failure of local or non-specific anti-inflammatory therapy, because DMARD have not been proved efficacious, even though they have been little studied. ${ }^{31}$ There are very few data regarding this subgroup of patients, but the efficacy of TNF inhibitors on these manifestations of PsA has been reported in several trials, generally as secondary endpoints. ${ }^{31}$ The diagnosis of enthesitis can be challenging; several instruments have been proposed for the assessment of enthesitis. ${ }^{14}$ There is no datadriven definition of 'active' disease in this case; we suggest to focus on quality of life in this regard. Therefore, physicians must apply clinical judgement when faced with dactylitis/enthesitis, aiming at the improvement of physical disability and quality of life, which can be severely impaired in some situations, such as enthesitis of the Achilles tendon. The group is of course not suggesting that all such patients should be treated with TNF inhibitors, as this would lead to the inappropriate use of TNF inhibitors in some situations. This recommendation, and recommendation 8 , received the lowest agreement within the group (see table 1 ).

\section{Axial disease and TNF inhibitors}

Recommendation 7 deals with the subgroup of patients who have predominant axial disease. In these patients, TNF inhibitors 
Table 2 Research agenda for PsA

\begin{tabular}{ll}
\hline Theme & Research questions \\
\hline Diagnosis & Defining screening strategies for PsA among psoriasis \\
patients: is screening needed and if so, how and when? & Diagnosing PsA versus RA with concomitant psoriasis \\
& Defining prognostic factors related to the risk of progressive \\
disease, structural damage and bad functional outcome in \\
early (and established) PsA \\
Pregnosis \\
NSAID, to DMARD, to biological agents) \\
Assessment of spinal disease: defining the similarities and \\
differences with ankylosing spondylitis \\
Defining disease severity \\
Defining the relationship between inflammation and structural
\end{tabular}
damage in PsA

Exploring juvenile PsA: is it different from adult-onset PsA? Identification of new therapeutic targets

Biomarkers Determining biomarkers related to damage, prognosis and treatment response

Treatment strategy Defining and evaluating the utility of tight control strategies in PsA

Assessing efficacy and safety of combinations of DMARD and of DMARD with biological agents

Evaluating the need for early treatment in PsA: who should be treated with DMARD? When to treat with DMARD?

Outcomes Patient-reported outcomes in PsA (which ones are important?), composite patient-reported scores in PsA, fatigue in PsA

Defining treatment targets

Defining (residual) active disease

Defining remission and predictors of remission

Synthetic DMARD Need for more RCT with DMARD (eg, methotrexate) to obtain more data on efficacy and toxicity

Assessing efficacy and safety of combination therapy of synthetic DMARD

Need for DMARD studies in MRI-positive early axial PsA

Biological agents Efficacy of combining DMARD with biological agents, compared with biological monotherapy and DMARD monotherapy

Defining the best indication for biological agents, when to start?

Defining the optimal duration of biological therapy, including addressing biological agent discontinuation (need for respective controlled trials)

Assessing the possibility of maintenance therapy with lower doses of biological agents

Assessing the efficacy and toxicity of new biological agents (including more data on ustekinumab, tocilizumab, abatacept, rituximab)

Through registry-based studies, assessing the safety of biological agents in PsA

Systemic Assessing the risk of skin flares related to systemic glucocorticoids glucocorticoids and in particular at low doses Assessing the benefit/risk ratio of long term glucocorticoid therapy

Assessing the efficacy and toxicity of intramuscular glucocorticoids in PsA

Other systemic Assessing the efficacy of miscellaneous drugs, for example, treatments

Local treatments oral vitamin $D^{73} 74$

Radiation synovectomy: evaluating its efficacy in monoarthritis of the knee

Comorbidities

Understanding the risk of cardiovascular disease in PsA and the modification of such risk according to disease activity and therapy

Assessing the risk and consequences of metabolic syndrome in PsA

Addressing tolerated consumption of alcohol in PsA in particular when treating by methotrexate

Imaging Defining the optimal use of radiographic scores

Evaluating the usefulness of MRI and ultrasonography, as well as developing scoring techniques for these imaging modalities

DMARD, disease-modifying antirheumatic drug; NSAID, non-steroidal anti-inflammatory drug; PsA, psoriatic arthritis; RA, rheumatoid arthritis; RCT, randomised controlled trial. can be considered even if no synthetic DMARD have been tried. This was extrapolated from data in ankylosing spondylitis, ${ }^{27}$ which also included patients with psoriasis. In PsA, the efficacy of TNF inhibitors on axial disease has been reported only in observational studies ${ }^{64}$ Active disease, here, refers to Bath ankylosing spondylitis disease activity index (BASDAI) levels equal to or above $4 .{ }^{65} 66$ The group suggests following established recommendations for ankylosing spondylitis. ${ }^{65} 66$

\section{TNF inhibitors exceptionally for a very active patient naive of} disease-modifying treatment

In certain, very rare and thus highly selected patients, there may be a place for TNF inhibitors as first-line treatment. This recommendation is mere expert opinion because there are no data in this regard. In TNF inhibitor trials, some patients were in fact DMARD-naive but the results regarding efficacy and safety have never been presented separately for these patients.

Some criteria to help select the patients who may need TNF inhibitors early were discussed, such as contraindications to synthetic DMARD or poor prognostic factors in conjunction with severe skin disease or severe extra-articular manifestations with a professional need for very rapid improvement. This item received the second lowest agreement and warrants further research.

\section{Switching to another TNF inhibitor agent}

This recommendation is derived from some studies indicating a good efficacy of a second TNF inhibitor in PsA. ${ }^{67} 68$ The recommendation is also extrapolated from the data available regarding switches in RA. ${ }^{69}$ To date, the group could not identify randomised trials in which switching was appropriately compared between different TNF inhibitors, and therefore a preference for a particular TNF inhibitor in this situation cannot be established.

\section{Accounting for comorbidities and safety issues}

Treatment of patients with PsA should be tailored according to the current manifestations of the disease (such as peripheral joint, skin, axial, entheseal symptoms or dactylitis), the level of current symptoms, clinical findings and prognostic indicators; but also according to the general clinical status (age, gender, comorbidity, concomitant medications, psychosocial factors). For each treatment, a careful choice must be made, taking into account efficacy, safety and cost issues.

The recommendations reflect the balance of efficacy and safety and do not deal in detail with the toxicity of DMARD and biological agents. In this regard, the most important pieces of information are provided in the separate publication on the systematic literature reviews, ${ }^{31}$ which indeed are part and parcel of these recommendations, because they provide their bases. Therefore, the recommendations shown here primarily deal with agents whose toxicity appears to be manageable, assuming that users are either aware of the respective risks or will adhere to the information provided in the package inserts. When deemed of particular importance, safety issues were especially mentioned (liver toxicity on methotrexate, infections with biological agents), but clearly safety has not been comprehensively addressed.

Some comorbidities require further exploration and were put on the research agenda; these include the cardiovascular risk in PsA, which has been little studied: cardiovascular diseases and their risk factors appear more common in patients with PsA than in controls. ${ }^{70-72}$ The contribution of alcohol consumption, type II diabetes, obesity and steatohepatitis to hepatotoxicity in PsA is also a relevant question, particularly 
in the light of the high prevalence of methotrexate use in this disease. ${ }^{50}$

\section{Graphic representation of the recommendations}

The recommendations and the algorithm they imply are summarised in figure 1.

The figure attempts to capture the most important aspects of the recommendations and explanatory text. While it does not account for all therapeutic eventualities nor ought to be representative for all variations of the disease, the relatively high level of agreement obtained within the group (see supplementary text 3 , available online only) suggests that it has validity for a large majority of patients with PsA.

\section{Research agenda}

One of the objectives of this initiative was to develop a research agenda, to guide future research funding by EULAR. An extensive research agenda was developed and the summary is presented in table 2 .

\section{DISCUSSION}

The task force has formulated 10 statements on the management of PsA. These statements were based on systematic literature reviews, but also on expert opinion with subsequent consensus finding on the wording of the recommendations. By this process and by stating the respective levels of evidence and strength of recommendation for each item, the committee adhered to the EULAR standardised operating procedures for the development of recommendations. Moreover, when evidence was lacking and the task force had to use only expert opinion, a research agenda was formulated to expedite the generation of evidence in the future.

The reasoning behind each statement and, particularly, behind the recommendations' specific wordings is explained in detail in the Results section. Importantly, the overall agreement with these statements, assessed anonymously several weeks after their formulation, was very high.

It is worth noting that the task force felt the best evidence for efficacy was available for three synthetic DMARD (methotrexate, leflunomide and sulfasalazine; statement 2) and four TNF inhibitors (adalimumab, etanercept, golimumab, infliximab; statements 5-7). Some additional synthetic DMARD agents are mentioned in the text only, because although effective in RA, their efficacy appeared to be lower or toxicity higher than that of other agents in their general class, and the data were often sparse.

The task force was convinced that modern therapy of PsA should be target oriented and governed by a strategic treatment approach. Remission or at least low disease activity, if remission cannot be attained, was affirmed as the therapeutic goal, in line with recommendations in RA. ${ }^{30}$ However, the literature review found few data regarding the natural history, prognosis, treatment targets and treatment strategies in PsA, ${ }^{31}$ contrary to the situation in RA. Still, there are some data supporting low disease activity or minimal disease activity as a therapeutic goal..$^{7-79}$ Furthermore, monotherapy with all TNF inhibitors usually leads to complete cessation of erosion progression at the group level; these agents appear to induce an arrest in disease progression. ${ }^{31}$ Finally, treatment targets constitute yet another part of the research agenda.

Glucocorticoids had a special place in the discussion (statement 4). Although there is a fear of psoriasis flares related to systemic glucocorticoids in PsA (and especially their cessation), we did not find supportive data in this regard, and the experience of rheumatologists and dermatologists may be different, possibly related to different forms of PsA (with low to moderate skin involvement on the one hand vs important or severe skin involvement on the other). Indeed, the experts in the group did not report their patients having experienced skin flares; and registry data show us that systemic glucocorticoids are in fact widely used at low doses in PsA. ${ }^{55}$

The present EULAR recommendations have been developed by experts (mainly rheumatologists, a dermatologist, an infectious disease specialist, a health professional and two patient representatives) from 14 European countries and the USA. It is therefore a true international document, meant to serve physicians in Europe and the world, although we are aware of the fact that not all agents mentioned here are available or accessible everywhere.

Beyond physicians, the document is also aimed at patients with PsA so they are informed on current treatment goals, strategies and opportunities. Importantly, patient representatives also participated in the task force. Finally, this document is also meant to inform officials in governments, social security agencies and reimbursement agencies.

The recommendations on the management of PsA provided here by the EULAR task force, when compared with those provided by GRAPPA, ${ }^{20}$ are of lesser complexity and thus more easy to adhere to; moreover, they cover additional aspects of drug therapies as well as therapeutic strategies and goals. A graphic representation (see figure 1) captures most of the important items.

The limitations of the present recommendations include that juvenile PsA and patients with psoriasis and some joint pain but without a definitive diagnosis of PsA are outside their scope; that topical treatments including topical NSAID and topical steroids are not taken into account and that non-pharmacological therapy is not considered. However, the group did state that non-pharmacological therapy was an important component of PsA treatment.

These recommendations reflect the current state of evidence and thought in the area of PsA management. The five overarching principles and 10 practical recommendations have a high level of face validity and feasibility, and the development of a scientific agenda will guide future research. However, several of the recommendations are strongly based on expert opinion, which in turn is based on clinical practice that has emerged in certain institutions, rather than available evidence. This is due to the paucity of data in the field of PsA. Therefore, the research agenda developed is extensive.

Finally, as has been the case over the past decade, it is to be anticipated that new data on existing or new drugs or therapeutic strategies will emerge over the next few years. Therefore, we will carefully observe the developments in the field and assume that an amendment of these recommendations may be needed in 2-5 years.

\section{Funding This study was supported by EULAR.}

Competing interests The following authors declare that they have no potential conflict of interest: CG-V, ZA, HD, MM, DB. The following authors declare a potential conflict of interest having received grant support and/or honoraria for consultations and/or for presentations as indicated: LG: Abbott, BMS, Chugai, MSD, Pfizer, Roche, Schering-Plough, UCB, Wyeth; JSS: Abbott, BMS, Chugai, MSD, Pfizer, Roche, Sanofi-Aventis, Schering-Plough, UCB, Wyeth; HM-O: Abbott, Centocor, Chugai, MSD, Pfizer; DVDH:Abbott, Amgen, Astra Zeneca, BMS, Centocor, Chugai, Eli lilly, GSK, Merck, Novartis, Otsuka, Pfizer, Roche, Schering-Plough, UCB, Wyeth; OF: Abbott, BMS, Pfizer, Merck, UCB; DA: Abbott, Roche, Schering-Plough, BMS, UCB, Sanofi-Aventis; MB: Roche, Abbott, BMS, Wyeth; PB: Abbott, Pfizer, Roche Sonobite, Wyeth; JB: Abbott, Centocor,Chugai, Merck, MSD, Novartis, Pfizer, Roche, UCB; FCB: Abbott, Schering-Plough, Wyeth; GB: Abbott, BMS, Chugai, MSD, Pfizer, 
Roche, Sanofi-Aventis, Schering Plough, UCB, Wyeth; JDC: Abbott, BMS, MSD, Roche; MdeW: Abbott, Roche, Wyeth; KdeV: Abbott, BMS, Celgene, Novartis, Pfizer, UCB; MD: Abbott, BMS, Novartis, Nordic Pharma, Pfizer, Roche, UCB, Wyeth; PH: Abbott, BMS, Pfizer, Schering Plough, UCB, Wyeth; AK: Abbott, Amgen, Centocor, Roche, UCB; TKK: Abbott, BMS, MSD, Pfizer, Roche, UCB; RL: Abbott, Amgen, BMS, Centocor, Merck, Pfizer, Schering-Plough, UCB, Wyeth; TL: Abbott, Almirall-Hermal, Basilea, Biogenldec, Ceries, Galderma, Innéov, Janssen-Cilag, Leo Pharma, Maruho, MSD, Novartis, Palau Pharma, Pfizer, Shionogi, Symrise, Wolff; DMcG: Merck, Pfizer Roche, Schering-Plough, Wyeth; INMcH: Abbott, Schering-Plough; IBMcl: Abbott, BMS, Merck, Pfizer, Roche; CR: Abbott, Amgen, BMS, Centocor, Pfizer, UCB; JS: Abbott, BMS, Centocor, MSD, Pfizer, Roche, Sanofi-Aventis, UCB; PPT: Abbott, Amgen, Centocor, Pfizer, Schering-Plough, Wyeth; GV: Abbott, BMS, Roche, MSD, Schering-Plough, UCB, Wyeth; JV: Abbott, BMS, MSD, Pfizer, Roche, UCB; KLW: Genentech, Wyeth; AZ: Abbott, Amgen, BMS, Essex/Schering-Plough, Merck, Pfizer, Roche, Sanofi-Aventis, UCB, Wyeth; PE: Abbott, BMS, Centocor, Pfizer, Roche, SanofiAventis, Schering-Plough,UCB, Wyeth.

Provenance and peer review Not commissioned; externally peer reviewed.

Author affi liations ${ }^{1}$ Paris Descartes University, Paris, France

${ }^{2}$ APHP, Rheumatology B Department, Cochin Hospital, Paris, France

${ }^{3}$ Division of Rheumatology, Department of Medicine 3, Medical University of Vienna, Vienna, Austria

${ }^{4}$ 2nd Department of Medicine, Hietzing Hospital, Vienna, Austria

${ }^{5}$ Paris 6 - Pierre et Marie Curie University, Paris, France

${ }^{6}$ Department of Rheumatology, Pitié-Salpêtrière Hospital, Paris, France

${ }^{7}$ Section of Musculoskeletal Disease, Leeds Institute of Molecular Medicine,

University of Leeds, Leeds, UK

${ }^{8}$ NIHR Leeds Musculoskeletal Biomedical Research Unit, Leeds Teaching Hospitals

Trust, Leeds, UK

${ }^{9}$ Department of Rheumatology, Leiden University Medical Centre, Leiden, The Netherlands

${ }^{10}$ Department of Rheumatology, St Vincent's University Hospital and Conway Institute, University College Dublin, Dublin, Ireland

${ }^{11} 3$ rd Rheumatology Department, National Institute of Rheumatology and

Physiotherapy, Budapest, Hungary

${ }^{12}$ Rheumatology, Clinical Immunology and Allergy, University of Crete, Faculty of Medicine, Heraklion, Greece

${ }^{13}$ Rheumazentrum Ruhrgebiet, Herne and Ruhr-Universität Bochum, Bochum,

Germany

${ }^{14}$ Department of Rheumatology and Clinical Immunology, Charité - University

Medicine, Berlin, Germany

${ }^{15}$ Arthritis Unit, Department of Rheumatology, Hospital Clínic and IDIBAPS, Barcelona, Spain

${ }_{16}$ People with Arthritis/Rheumatism in Europe (PARE), Zurich, Switzerland

${ }^{17}$ Department of Rheumatology, Diakonhjemmet Hospital, Oslo, Norway

${ }^{18}$ Faculty of Medicine, University of Oslo, Oslo, Norway

${ }^{19}$ Department of Rheumatology, University Hospitals, Leuven, Belgium

${ }^{20}$ Division of Rheumatology, Allergy, Immunology, University of California, San Diego, California, USA

${ }^{21}$ Department of Internal Medicine/Rheumatology, University Hospital Maastricht, Maastricht, The Netherlands

${ }^{22}$ Department of Dermatology, University Hospital Münster, Münster, Germany

${ }^{23}$ A.DI.PSO. (Associazione per la Difesa degli Psoriasici) - PE.Pso.POF (Pan European

Psoriasis Patients' Organization Forum), Rome, Italy

${ }^{24}$ Department of Rheumatology, Royal National Hospital for Rheumatic Diseases,

Bath, UK

${ }^{25}$ Institute of Infection, Immunity and Inflammation, University of Glasgow, Glasgow, UK

${ }^{26}$ Allergy, Immunology and Rheumatology Division, University of Rochester Medical Center, Rochester, New York, USA

${ }^{27}$ Rheumatology, Campus Benjamin Franklin, Charité, Berlin, Germany

${ }^{28}$ Division of Clinical Immunology and Rheumatology, Academic Medical Center/

University of Amsterdam, Amsterdam, The Netherlands

${ }^{29}$ Department of Internal Medicine/ Rheumatology Unit, La Sapienza University of

Rome, Rome, Italy

${ }^{30}$ Institute of Rheumatology, Prague, Czech Republic

${ }^{31}$ Department of Infectious Diseases, Public Health and Preventive Medicine, Oregon

Health and Science University, Portland, Oregon, USA

${ }^{32}$ German Rheumatism Research Centre, Berlin, Germany

${ }^{33}$ Department of Rheumatology and Clinical Immunology, Charité - University

Medicine Berlin, Berlin, Germany

\section{REFERENCES}

1. Kavanaugh A, Antoni CE, Gladman D, et al. The Infliximab Multinational Psoriatic Arthritis Controlled Trial (IMPACT): results of radiographic analyses after 1 year. Ann Rheum Dis 2006;65:1038-43.
2. Mease $\mathbf{P J}$, Goffe BS, Metz J, et al. Etanercept in the treatment of psoriatic arthritis and psoriasis: a randomised trial. Lancet 2000;356:385-90.

3. Antoni C, Krueger GG, de Vlam K, et al. Infliximab improves signs and symptoms of psoriatic arthritis: results of the IMPACT 2 trial. Ann Rheum Dis 2005;64:1150-7.

4. Kaltwasser JP, Nash P, Gladman D, et al. Efficacy and safety of leflunomide in the treatment of psoriatic arthritis and psoriasis: a multinational, double-blind, randomized, placebo-controlled clinical trial. Arthritis Rheum 2004;50:1939-50.

5. Mease PJ, Gladman DD, Ritchlin CT, et al. Adalimumab for the treatment of patients with moderately to severely active psoriatic arthritis: results of a double-blind, randomized, placebo-controlled trial. Arthritis Rheum 2005:52:3279-89.

6. Kavanaugh A, Mclnnes I, Mease P, et al. Golimumab, a new human tumor necrosis factor alpha antibody, administered every four weeks as a subcutaneous injection in psoriatic arthritis: twenty-four-week efficacy and safety results of a randomized, placebo-controlled study. Arthritis Rheum 2009;60:976-86.

7. Mease PJ, Gladman DD, Keystone EC. Alefacept in combination with methotrexate for the treatment of psoriatic arthritis: results of a randomized, double-blind, placebocontrolled study. Arthritis Rheum 2006;54:1638-45.

8. Menter A, Korman NJ, Elmets CA, et al. Guidelines of care for the management of psoriasis and psoriatic arthritis: section 4. Guidelines of care for the management and treatment of psoriasis with traditional systemic agents. J Am Acad Dermatol 2009:61:451-85

9. Jones G, Crotty M, Brooks P. Interventions for psoriatic arthritis. Cochrane Database Syst Rev 2000;3:CD000212.

10. Gottlieb A, Menter A, Mendelsohn A, et al. Ustekinumab, a human interleukin 12/23 monoclonal antibody, for psoriatic arthritis: randomised, double-blind, placebocontrolled, crossover trial. Lancet 2009;373:633-40.

11. Peeters AJ, Dijkmans BA, van der Schroeff JG. Fumaric acid therapy for psoriatic arthritis. A randomized, double-blind, placebo-controlled study. Br J Rheumatol 1992;31:502-4

12. Menter A, Korman NJ, Elmets CA, et al. Guidelines of care for the management of psoriasis and psoriatic arthritis: section 5 . Guidelines of care for the treatment of psoriasis with phototherapy and photochemotherapy. J Am Acad Dermatol 2010;62:114-35.

13. Wright V, Moll JM. Psoriatic arthritis. Bull Rheum Dis 1971;21:627-32

14. Van den Bosch F, Cryssen BV, Mielants H. Clinical assessment in the spondyloarthropathies, including psoriatic arthritis. Curr Opin Rheumatol 2006;18:354-8

15. McGonagle D, Conaghan PG, Emery P. Psoriatic arthritis: a unified concept twenty years on. Arthritis Rheum 1999;42:1080-6.

16. Antoni CE, Kavanaugh A, Kirkham B, et al. Sustained benefits of infliximab therapy for dermatologic and articular manifestations of psoriatic arthritis: results from the infliximab multinational psoriatic arthritis controlled trial (IMPACT). Arthritis Rheum 2005; 52:1227-36.

17. Gladman DD, Mease PJ, Ritchlin CT, et al. Adalimumab for long-term treatment of psoriatic arthritis: forty-eight week data from the adalimumab effectiveness in psoriatic arthritis trial. Arthritis Rheum 2007;56:476-88.

18. Gladman DD, Mease PJ, Cifaldi MA, et al. Adalimumab improves joint-related and skin-related functional impairment in patients with psoriatic arthritis: patient-reported outcomes of the Adalimumab Effectiveness in Psoriatic Arthritis Trial. Ann Rheum Dis 2007;66:163-8.

19. Furst DE, Keystone EC, Fleischmann R, et al. Updated consensus statement on biological agents for the treatment of rheumatic diseases, 2009. Ann Rheum Dis 2010;69(Suppl 1):i2-29.

20. Ritchlin CT, Kavanaugh A, Gladman DD, et al. Treatment recommendations for psoriatic arthritis. Ann Rheum Dis 2009;68:1387-94.

21. Kavanaugh AF, Ritchlin CT. Systematic review of treatments for psoriatic arthritis: an evidence based approach and basis for treatment guidelines. J Rheumatol 2006;33:1417-21.

22. Fraser AD, van Kuijk AW, Westhovens $R$, et al. A randomised, double blind, placebo controlled, multicentre trial of combination therapy with methotrexate plus ciclosporin in patients with active psoriatic arthritis. Ann Rheum Dis 2005;64:859-64.

23. Gladman DD, Mease PJ, Healy P, et al. Outcome measures in psoriatic arthritis. J Rheumatol 2007;34:1159-66.

24. Nash P. Assessment and treatment of psoriatic spondylitis. Curr Rheumatol Rep 2009;11:278-83.

25. Gladman DD, Landewé R, McHugh NJ, et al. Composite measures in psoriatic arthritis: GRAPPA 2008. J Rheumatol 2010;37:453-61.

26. Dougados M, Betteridge N, Burmester GR, et al. EULAR standardised operating procedures for the elaboration, evaluation, dissemination, and implementation of recommendations endorsed by the EULAR standing committees. Ann Rheum Dis 2004:63:1172-6.

27. Zochling J, van der Heijde D, Burgos-Vargas R, et al. ASAS/EULAR recommendations for the management of ankylosing spondylitis. Ann Rheum Dis 2006;65:442-52.

28. Zhang W, Doherty $\mathrm{M}$, Arden $\mathrm{N}$, et al. EULAR evidence based recommendations for the management of hip osteoarthritis: report of a task force of the EULAR Standing 
Committee for International Clinical Studies Including Therapeutics (ESCISIT). Ann Rheum Dis 2005;64:669-81.

29. Combe B, Landewe R, Lukas C, et al. EULAR recommendations for the management of early arthritis: report of a task force of the European Standing Committee for International Clinical Studies Including Therapeutics (ESCISIT). Ann Rheum Dis 2007;66:34-45.

30. Smolen JS, Landewé R, Breedveld FC, et al. EULAR recommendations for the management of rheumatoid arthritis with synthetic and biological disease-modifying antirheumatic drugs. Ann Rheum Dis 2010;69:964-75.

31. Ash Z, A systematic literature review of conventional and biologic drug therapies for the treatment of psoriatic arthritis: current evidence informing the EULAR recommendations for the management of Psoriatic Arthritis. Ann Rheum Dis.

32. Kivitz AJ, Espinoza LR, Sherrer YR, et al. A comparison of the efficacy and safety of celecoxib $200 \mathrm{mg}$ and celecoxib $400 \mathrm{mg}$ once daily in treating the signs and symptoms of psoriatic arthritis. Semin Arthritis Rheum 2007:37:164-73.

33. Sarzi-Puttini P, Santandrea S, Boccassini L, et al. The role of NSAIDs in psoriatic arthritis: evidence from a controlled study with nimesulide. Clin Exp Rheumatol 2001;19(1 Suppl 22):S17-20.

34. Borer JS, Simon LS. Cardiovascular and gastrointestinal effects of COX-2 inhibitors and NSAIDs: achieving a balance. Arthritis Res Ther 2005;7(Suppl 4):S14-22.

35. Latimer N, Lord J, Grant RL, et al. Cost effectiveness of COX 2 selective inhibitors and traditional NSAIDs alone or in combination with a proton pump inhibitor for people with osteoarthritis. BMJ 2009;339:b2538.

36. Strand V. Are COX-2 inhibitors preferable to non-selective non-steroidal antiinflammatory drugs in patients with risk of cardiovascular events taking low-dose aspirin? Lancet 2007:370:2138-51.

37. Gladman DD, Farewell VT. Progression in psoriatic arthritis: role of time varying clinical indicators. J Rheumatol 1999;26:2409-13.

38. Lard LR, Visser H, Speyer I, et al. Early versus delayed treatment in patients with recent-onset rheumatoid arthritis: comparison of two cohorts who received different treatment strategies. Am J Med 2001;111:446-51.

39. Scarpa R, Peluso R, Atteno M, et al. The effectiveness of a traditional therapeutical approach in early psoriatic arthritis: results of a pilot randomised 6-month trial with methotrexate. Clin Rheumatol 2008;27:823-6.

40. Lie E, van der Heijde D, Uhlig T, et al. Effectiveness and retention rates of methotrexate in psoriatic arthritis in comparison with methotrexate-treated patients with rheumatoid arthritis. Ann Rheum Dis 2010;69:671-6.

41. Black RL, O'Brien WM, Vanscott EJ, et al. Methotrexate therapy in psoriatic arthritis; double-blind study on 21 patients. JAMA 1964:189:743-7.

42. Willkens RF, Williams HJ, Ward JR, et al. Randomized, double-blind, placebo controlled trial of low-dose pulse methotrexate in psoriatic arthritis. Arthritis Rheum 1984:27:376-81.

43. Visser K, van der Heijde D. Optimal dosage and route of administration of methotrexate in rheumatoid arthritis: a systematic review of the literature. Ann Rheum Dis 2009;68:1094-9.

44. Fraser SM, Hopkins R, Hunter JA, et al. Sulphasalazine in the management of psoriatic arthritis. Br J Rheumatol 1993;32:923-5.

45. Gupta AK, Grober JS, Hamilton TA, et al. Sulfasalazine therapy for psoriatic arthritis: a double blind, placebo controlled trial. J Rheumatol 1995;22:894-8.

46. Salvarani C, Macchioni P, Olivieri I, et al. A comparison of cyclosporine, sulfasalazine, and symptomatic therapy in the treatment of psoriatic arthritis. $J$ Rheumatol 2001:28:2274-82.

47. Clark CM, Kirby B, Morris AD, et al. Combination treatment with methotrexate and cyclosporin for severe recalcitrant psoriasis. Br J Dermatol 1999;141:279-82.

48. Helliwell PS, Taylor WJ. Treatment of psoriatic arthritis and rheumatoid arthritis with disease modifying drugs - comparison of drugs and adverse reactions. $J$ Rheumatol 2008;35:472-6.

49. Whiting-0'Keefe $\mathbf{O E}$, Fye KH, Sack KD. Methotrexate and histologic hepatic abnormalities: a meta-analysis. Am J Med 1991;90:711-16

50. Curtis JR, Beukelman T, Onofrei A, et al. Elevated liver enzyme tests among patients with rheumatoid arthritis or psoriatic arthritis treated with methotrexate and/or leflunomide. Ann Rheum Dis 2010:69:43-7.

51. Rosenberg P, Urwitz H, Johannesson A, et al. Psoriasis patients with diabetes type 2 are at high risk of developing liver fibrosis during methotrexate treatment. $J$ Hepatol 2007:46:1111-18.

52. Heydendael VM, Spuls PI, Opmeer BC, et al. Methotrexate versus cyclosporine in moderate-to-severe chronic plaque psoriasis. N Eng/ J Med 2003;349:658-65.

53. Eder L, Chandran V, Ueng J, et al. Predictors of response to intra-articular steroid injection in psoriatic arthritis. Rheumatology (Oxford) 2010;49:1367-73.

54. Fredriksson T, Pettersson U. Severe psoriasis - oral therapy with a new retinoid. Dermatologica 1978;157:238-44.

55. Zink A, Thiele K, Huscher D, et al. Healthcare and burden of disease in psoriatic arthritis. A comparison with rheumatoid arthritis and ankylosing spondylitis. J Rheumatol 2006:33:86-90.
56. Hoes JN, Jacobs JW, Verstappen SM, et al. Adverse events of low- to mediumdose oral glucocorticoids in inflammatory diseases: a meta-analysis. Ann Rheum Dis 2009:68:1833-8.

57. Hoes JN, Jacobs JW, Boers M, et al. EULAR evidence-based recommendations on the management of systemic glucocorticoid therapy in rheumatic diseases. Ann Rheum Dis 2007;66:1560-7.

58. Glintborg B, Ostergaard M, Dreyer L, et al. Treatment response, drug survival and predictors thereof in 764 patients with psoriatic arthritis treated with anti-tumor necrosis factor a therapy: Results from the Danish nationwide DANBIO registry. Arthritis Rheum 2011:63:382-90.

59. Griffiths CE, Strober BE, van de Kerkhof $\mathrm{P}$, et al. Comparison of ustekinumab and etanercept for moderate-to-severe psoriasis. N Engl J Med 2010;362:118-28.

60. Heiberg MS, Koldingsnes W. Mikkelsen K, et al. The comparative one-year performance of anti-tumor necrosis factor alpha drugs in patients with rheumatoid arthritis, psoriatic arthritis, and ankylosing spondylitis: results from a longitudinal, observational, multicenter study. Arthritis Rheum 2008:59:234-40.

61. Mease PJ, Ory P, Sharp JT, et al. Adalimumab for long-term treatment of psoriatic arthritis: 2-year data from the Adalimumab Effectiveness in Psoriatic Arthritis Trial (ADEPT). Ann Rheum Dis 2009:68:702-9.

62. Mease PJ, Kivitz AJ, Burch FX, et al. Continued inhibition of radiographic progression in patients with psoriatic arthritis following 2 years of treatment with etanercept. J Rheumatol 2006;33:712-21.

63. Antoni CE, Kavanaugh A, van der Heijde D, et al. Two-year efficacy and safety of infliximab treatment in patients with active psoriatic arthritis: findings of the Infliximab Multinational Psoriatic Arthritis Controlled Trial (IMPACT). J Rheumatol 2008:35:869-76.

64. Olivieri I, de Portu S, Salvarani C, et al. The psoriatic arthritis cost evaluation study: a cost-of-illness study on tumour necrosis factor inhibitors in psoriatic arthritis patients with inadequate response to conventional therapy. Rheumatology (Oxford) 2008:47:1664-70.

65. Braun J, Davis J, Dougados M, et al. First update of the international ASAS consensus statement for the use of anti-TNF agents in patients with ankylosing spondylitis. Ann Rheum Dis 2006:65:316-20.

66. Braun J, Pham T, Sieper J, et al. International ASAS consensus statement for the use of anti-tumour necrosis factor agents in patients with ankylosing spondylitis. Ann Rheum Dis 2003;62:817-24.

67. Gomez-Reino JJ, Carmona L. Switching TNF antagonists in patients with chronic arthritis: an observational study of 488 patients over a four-year period. Arthritis Res Ther 2006;8:R29.

68. Saad AA, Ashcroft DM, Watson KD, et al. Persistence with anti-tumour necrosis factor therapies in patients with psoriatic arthritis: observational study from the British Society of Rheumatology Biologics Register. Arthritis Res Ther 2009;11:R52

69. Nam JL, Winthrop KL, van Vollenhoven RF, et al. Current evidence for the management of rheumatoid arthritis with biological disease-modifying antirheumatic drugs: a systematic literature review informing the EULAR recommendations for the management of RA. Ann Rheum Dis 2010;69:976-86.

70. Han C, Robinson DW, Jr , Hackett MV, et al. Cardiovascular disease and risk factors in patients with rheumatoid arthritis, psoriatic arthritis, and ankylosing spondylitis. J Rheumato/ 2006:33:2167-72.

71. Peters MJ, Symmons DP, McCarey D, et al. EULAR evidence-based recommendations for cardiovascular risk management in patients with rheumatoid arthritis and other forms of inflammatory arthritis. Ann Rheum Dis 2010;69:325-31.

72. Tam LS, Tomlinson B, Chu T, et al. Cardiovascular risk profile of patients with psoriatic arthritis compared to controls - the role of inflammation. Rheumatology (Oxford) 2008:47:718-23.

73. Gaál J, Lakos G, Szodoray P, et al. Immunological and clinical effects of alphacalcidol in patients with psoriatic arthropathy: results of an open, follow-up pilot study. Acta Derm Venereo/ 2009;89:140-4

74. Huckins D, Felson DT, Holick M. Treatment of psoriatic arthritis with oral 1,25dihydroxyvitamin D3: a pilot study. Arthritis Rheum 1990;33:1723-7.

75. Saber TP, Ng CT, Renard G, et al. Remission in psoriatic arthritis: is it possible and how can it be predicted? Arthritis Res Ther 2010;12:R94.

76. Cantini F, Niccoli L, Nannini C, et al. Criteria, frequency, and duration of clinical remission in psoriatic arthritis patients with peripheral involvement requiring secondline drugs. J Rheumatol Supp/ 2009;83:78-80.

77. Kavanaugh A, Fransen J. Defining remission in psoriatic arthritis. Clin Exp Rheumato 2006:24(6 Suppl 43):S83-7.

78. Coates LC, Cook R, Lee KA, et al. Frequency, predictors, and prognosis of sustained minimal disease activity in an observational psoriatic arthritis cohort. Arthritis Care Res (Hoboken) 2010;62:970-6.

79. Coates LC, Fransen J, Helliwell PS. Defining minimal disease activity in psoriatic arthritis: a proposed objective target for treatment. Ann Rheum Dis 2010;69:48-53. 